\title{
Transferring Our Cultural Heritage to the Next Generations via Visual Arts Education*
}

\author{
Seçil Kartopu \\ Bartın University, Bartın, Turkey \\ Hülya Iz Bölükoğlu \\ TOBB Economy and Technology University, Ankara, Turkey
}

\begin{abstract}
It is well known that the customs and traditions shared and maintained in a society reflect the culture of that society and also that it is a society's responsibility to convey its culture to the next generations. From this point of view, it can be further claimed that children's games, as indicators of cultural richness, are important sources for not only sustaining and maintaining the culture, but also for delivering cultural values and assets to future generations. The present study was planned and carried out to promote, improve, and protect the traditional children games and to have them used in education, so as to transfer these important cultural assets to future generations. Seventy students currently attending 4th, 7th, and 8th grades in Kurtuluş Primary School in Ankara Province were included in the study. These students were informed about the traditional children's games and then asked to conduct research. Later, the children were asked to convey these games to their paintings and drawings, thus, completing the teaching of the games by means of visual arts education. Findings gathered from the paintings and drawings of the children were evaluated to determine the achievements and effectiveness of the study.
\end{abstract}

Keywords: visual arts education, children games, cultural transfer, pictures of children

\section{Introduction}

It is obvious that today's technological advancements, speed of access to information, and globalisation have been changing the structure of society. This situation demands that every country safeguard its cultural heritage, cultural values, and accumulation of knowledge, and transfer these to new generations by enriching this heritage.

Every society has its cultural heritage shaped by its history. In Turkey, various cultures have been living together for many years without ignoring its own identities. This is a sign that we have a rich heritage in terms of culture and history. This encumbers us with the responsibility to transfer our cultural values to the new generations by maintaining them, as well.

Such games are played everywhere in the world, but they vary by era and the culture of any given place. Turkey has a very rich traditional game culture that features many different games from every region and

\footnotetext{
* This study is the arranged format of the poster presented in The 34th World Congress of the International Society for Education Through Art (InSEA 2014).

Seçil Kartopu, Dr., assistant professor, Faculty of Education, Department of Fine Arts, Bartın University.

Hülya Iz Bölükoğlu, professor, Faculty of Fine Arts, Design and Architecture, Department Chair of Visual Communication Design, TOBB Economy and Technology University.
} 
province. However, the social, political, and economic developments and changes of today's society, such as migration from rural areas to larger cities, as well as dramatic changes in technology, have caused many changes in children's games. Unfortunately, some of these significant cultural assets are now sinking into oblivion.

For this purpose, United Nations Educational, Scientific, and Cultural Organization (UNESCO), with its efforts to protect and transfer cultural heritage to future generations, adopted the "Convention for the Safeguarding of Intangible Cultural Heritage" on 17th of October, 2003. This convention was accepted unanimously in the Turkish National Assembly on the 19th of January, 2006, and Turkey became a party to it. In this convention, intangible cultural heritage refers to "the practices, representations, expressions, knowledge, and skills - as well as the instruments, objects, artifacts, and cultural spaces associated with them-that communities, groups, and in some cases, individuals recognize as part of their cultural heritage" (Erkal, 2010). Our traditional children's games, which are covered in this framework, are a product of a folk culture that is defined as an intangible cultural heritage, and thus, needs to be protected under this convention (Ersoy \& Oğuz, 2007).

Article 14 of this convention foresees the steps that need to be taken in relation to the topic of education. This article stipulates that the protection of intangible cultural heritage remains a part of formal and non-formal education programmes. "Education," a social fact in learning, enriching, and transferring our current cultural heritage and variety to the next generations, plays a key role. In this respect, the studies carried out in our educational institutes in order to raise the awareness towards the "protection of the non-material cultural heritage" are of vital importance (Ersoy \& Oğuz, 2007).

In the visual arts courses offered in our schools, students are in an environment where they can embrace and enrich their own culture, and transfer it to the next generations. In that, these courses provide them with an environment where there is interaction and communication among the students and they can use their creativity via in-class and extracurricular activities. In this respect, visual arts courses are an important factor in transferring traditional children's games to the new generations.

An important part of our culture, traditional children's games are entertaining acts where cognitive, affective, and kinaesthetic activities are all together. These games help improve interaction, communication, and creativity in children. They also have an important impact on children's socialisation and mental improvement. Children's games are defined as activities that socialize children and that facilitate their physical, cognitive, emotional, and psycho-motor development. They also increase the self-actualization, creativity, collaboration, and group participation skills of children. However, today, instead of outdoor spaces, children play indoors with their computers. This situation not only prevents children from learning social and ethical rules and many other important values, such as human communication and solidarity, but it also isolates the child who may then become addicted to virtual media. Violence, aggression, and computer games have become a serious issue in society. Time spent in front of television and computer screens has been causally linked to physical inactivity and obesity. Given the current prevalence of childhood overweight and obesity, such positive behaviours (improving children's outdoor play opportunities) should be encouraged (Graves, Stratton, Ridgers, \& Cable, 2008, pp. 1282-1283; Williams \& Clippinger, 2002, p. 495; Kalburan, 2014, p. 113).

The Ministry of National Education (MEB) states the importance of traditional children's games on students as such: 
A part of our own culture, traditional children's games which are forgotten, not played anymore in the modern city life restricting playgrounds are important in terms of:

1. Being a set of values positively teaching our children the concepts of competition, winning, and losing;

2. Securing that our rapidly increasing population will have a secure future as a happy, healthy, and conscious generation;

3. Helping diminish the negativities arising from the restriction of playgrounds in the modern city life;

4. Getting our children to adopt exercising habits at an early age;

5. By involving the adults into the children's games, increasing the intergenerational communication and sharing;

6. Having the child become a part of real life they voluntarily take part in and is the basis of her physical, cognitive, linguistic, emotional, and social development;

7. Being an efficient process for a child's learning;

8. Helping children develop free thinking abilities;

9. Teaching children to empathise with others, respect others and realise their own role in dialogues, be patient, abide by the rules, deal with stress, solve problems, and reinforce their leadership abilities;

10. Helping positively reinforce their character and personality development and communication abilities;

11. Helping children establish new friendships (MEB, 2013, p. 6).

\section{Method}

The participants of this study consist of 70 students who are studying at 4th and 7th grades at Ankara Kurtuluş Primary School in the school year 2013-2014.

This study is carried out and aims at promoting and protecting traditional children's games, one of our important cultural values, and transferring them to the next generations via visual arts education. This study also intends to decrease the behavioural problems observed in school by decreasing the addiction of students to the virtual world and saving them from their asociality and loneliness caused by developing technology and globalisation and getting them to learn their own cultural characteristics, improving and transferring them to the new generations.

\section{Stages of the Study}

This study was carried out on two groups of students, one group being in the 7th grade students (50 students), the other in the 4 th grade ( 20 students). The study lasted 10 weeks.

In the 1st stage of the study, the students were asked to do research about traditional children's games by asking the elders in their families about what games they played when they were children, what the rules for these games were, and how they were played.

At the 2nd week, the students were asked to report the answers to the above questions and bring them to class.

In the course of the study, the students stated that they not only talked to the elders in the family, but also to other older people in their neighbourhood. They also photographed their interviews with them.

The students explained and demonstrated to their friends whom they talked to, which games the interviewee played, and how the game was played. 
It has been observed that at this stage, students had a good time learning new games thanks to the study and did their research about this topic very eagerly.

In the next stage, these games compiled are studied and classified in terms of pedagogic value, the games suited for playing in the classroom were chosen; the students were put into groups and these groups were asked to do research about the rules of the games.

At the end of the student's research, it was seen that some games are named differently in different regions of Turkey where cultural diversity and richness are abundant. Some minor changes in the rules of the games were also observed.

In the 3rd week, the student groups that learned the games well explained them to the rest of the class and the games were played with the participation of the whole class.

In the 4th and 5th weeks, traditional children's games were played in the schoolyard with the permission of the school administration.

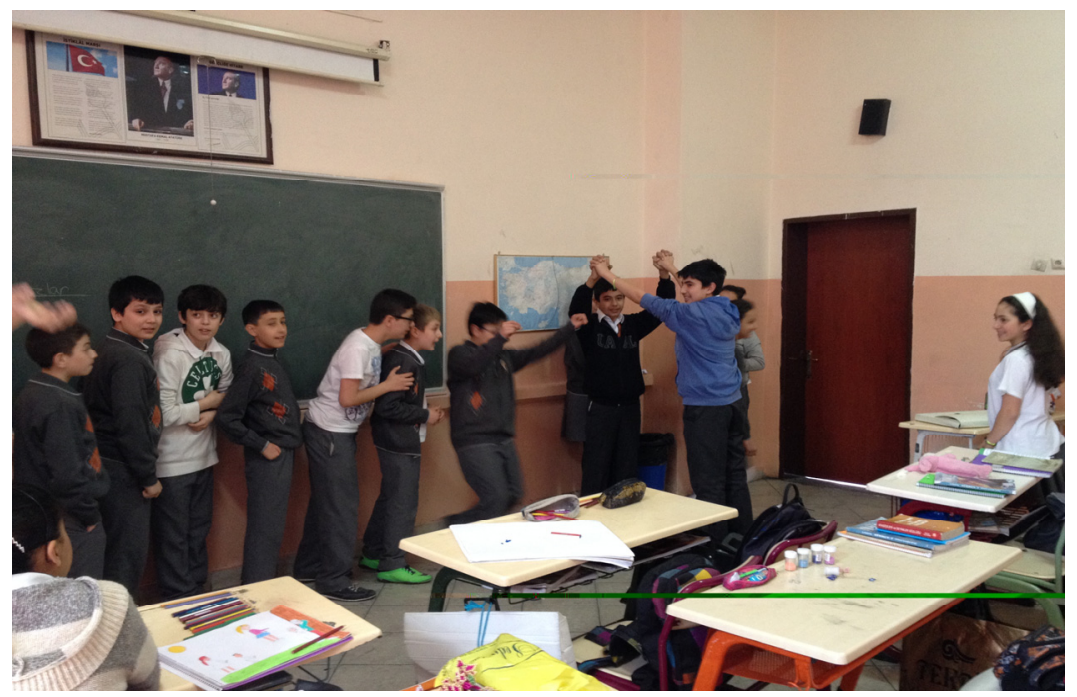

Figure 1. Traditional children's (games) plays performed in the classroom.

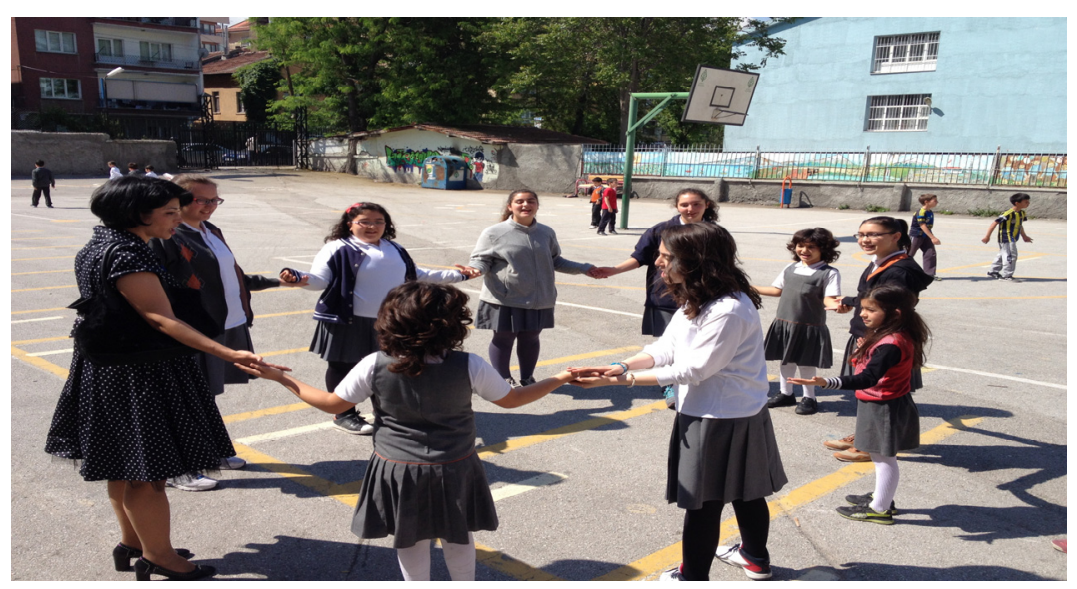

Figure 2. Traditional children's (games) plays performed in the schoolyard.

Figures 1 and 2 show our traditional children's (games) plays performed in the classrooms and school garden. 
It has been seen that the students had a lot fun playing these games in both the classroom and the schoolyard.

Some of the students who are more reserved or shy during classes joined the games playing along with their friends. These games revealed the students' leadership qualities and emphasized the importance of mutual communication.

In the 6 th and 7 th weeks, the students were asked to express their emotions related to the traditional children's games by illustrating them. As a tool, drawing paper was used and the drawing method was left to their choice.

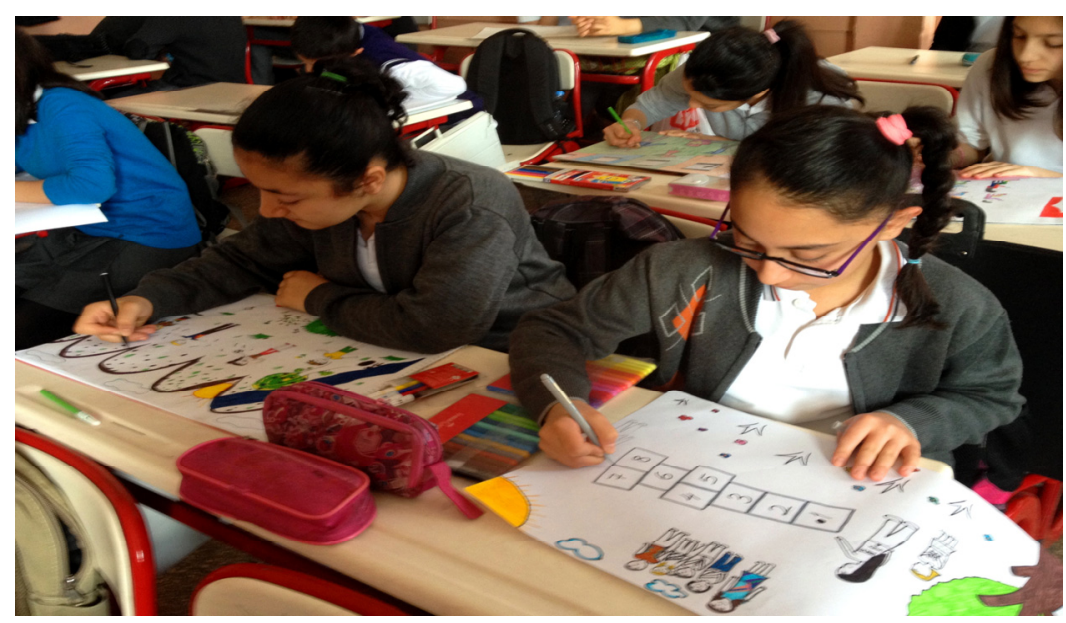

Figure 3. Traditional children's games being pictured by students.

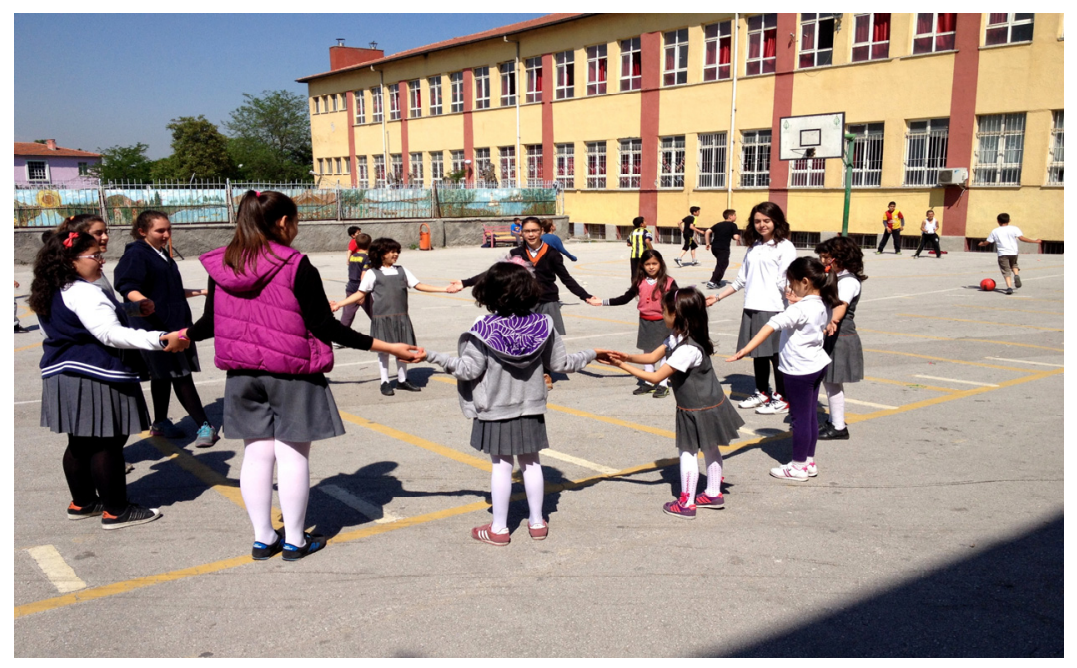

Figure 4 . Games are being taught by 7 th graders to the 4 th graders.

Figures 3 and 4 show our traditional children's games being pictured by students and games are being taught by 7 th graders to the 4 th graders.

In the 8th and 9th weeks, 7th grade students taught the games they learned to the 4th grade students. It was observed that 7 th grade students patiently and devotedly taught the games to the 4 th graders and, at the end, they played the games together.

Later, the 4th grade students were observed teaching these games to their friends in the other classes and playing the games together with them. 
In the last week, the study done with the students was reviewed and analysed, and pictures of the students were hung on the school board.

\section{Results and Conclusion}

Before participating in the study, the older students were less understanding towards the younger students at break times. After participating, however, we observed that the older students were not only more understanding towards the younger ones, but had developed a protective attitude toward them.

In the course of and following the study, we received a positive reaction from the other classes, and all the teachers of the low level classes wanted us to teach them these games.

The students who behaved badly and were difficult to control now play these games as a group, and the parents, teachers, and administration are very pleased with this situation.

Since the completion of the study, the school administration has set up the school's garden such that these games can be played more easily.

While the games were being played in the schoolyard, most passers-by sang along with the old folk riddles in the games as being played and applauded them. It was clear that the games reminded them of their own childhoods. This means that the games were accepted as a step in the transferral of culture.

At the end of the research, children identified with these games, which are a traditional element of our culture. As a result of the research that was conducted and its applications, the goal of popularizing these traditional children's games and transferral of our cultural heritage was attained.

\section{References}

Graves, L., Stratton, G., Ridgers, N. D., \& Cable, N. T. (2008). Energy expenditure in adolescents playing new generation computer games. British Journal of Sports Medicine, 42(7), 592-594.

Erkal, H. (2010). Study on the effects of UNESCO National Living Human Treasure Systems upon safeguarding of the intangible cultural heritage and transmission to next generations (Unpublished master's thesis, Gazi University Institute of Social Sciences, Ankara, Turkey).

Ersoy, P., \& Oğuz, M. Ö.(2007). Living Turkish traditional child games in 2004 (2nd ed.). Gazi University Turkish Folklore Research and Practice Centre (THBMER) Publications: Ankara, Turkey.

Kalburan, N. C. (2014). Young children's opportunities and parent's opinions regarding outdoor play. Journal of Social Policies, 32, 113-135.

Ministry of National Education (MEB). (2013). Traditional children's games festival guidebook (p. 6). Retrieved October 1, 2014, from from http://gulnar.meb.gov.tr/media/zincir/2014_01_10_5768_101.pdf

Williams, R. B., \& Clippinger, C. A. (2002). Aggression, competition and computer games: Computer and human opponents. Computers in Human Behavior, 18(5), 495-506. 